\title{
Chemical reporters for biological discovery
}

\author{
Markus Grammel ${ }^{1}$ and Howard C. Hang ${ }^{1,{ }^{*}}$ \\ ${ }^{1}$ Laboratory of Chemical Biology and Microbial Pathogenesis, The Rockefeller University, New \\ York, NY, 10065, USA.
}

\begin{abstract}
Functional tools are needed to understand complex biological systems. Here we review how chemical reporters in conjunction with bioorthogonal labeling methods can be used to image and retrieve nucleic acids, proteins, glycans, lipids and other metabolites in vitro, in cells as well as in whole organisms. By tagging these biomolecules, researchers can now monitor their dynamics in living systems and discover specific substrates of cellular pathways. These advances in chemical biology are thus providing important tools to characterize biological pathways and are poised to facilitate our understanding of human diseases.
\end{abstract}

\section{Introduction}

The genomic revolution has offered unprecedented opportunities to understand basic biology and human disease. With increasingly high-throughput and cost-effective sequencing methods, the genomes of many organisms and mutations associated with human diseases have been annotated. In parallel, large-scale gene deletion and overexpression studies as well as protein-protein interaction screens have uncovered complex signaling networks. These studies have not only revealed the genetic basis for many fundamental biological processes but have also presented new possibilities for personalized medicine. Nonetheless, significant challenges lay ahead for translating genetically encoded information into biological function and therapeutic development. At the nucleic acid level, many biological phenotypes are controlled by multiple genes that may not be readily apparent by perturbation of individual genes or alleles. Furthermore, the phenotype of interest may only be transient or controlled by epigenetic mechanisms via chromatin modifications or small RNAs not evident by reading the genetic code. To complicate matters further, the genomes of most organisms encode protein families with overlapping biochemical activities, which are often spatially and temporally regulated by specific interactions with other factors inside of cells or have cell-type specific functions in animals. Beyond nucleic acids and proteins, glycans, lipids and other small molecule cofactors are also important regulators of cellular function because they modify specific substrates that are often directly coupled to metabolism. Biological signaling pathways are therefore often not linear and typically comprise more complex positive and negative feedback networks to amplify or shutdown specific phenotypes. This biological complexity demands a better understanding of the chemistry inside cells and animals so we can decode their genomes and dissect their interactions with the environment. As new technologies have accelerated genomics, here we highlight advances in bioorthogonal chemical reporters that have enabled

*hhang@ rockefeller.edu.

Author contributions

M.G. and H.C.H. wrote this review.

Competing financial interests

The authors declare no competing financial interests. 
the imaging and functional analysis of nucleic acids, proteins, glycans, lipids and other metabolites in biology.

The advances in bioorthogonal chemistry have inspired a series of azide-, alkyne- and alkene-functionalized metabolites as chemical reporters for nucleic acids, proteins, glycans, lipids as well as other biomolecules (Box 1, Fig. 1) ${ }^{1,2}$. Key to this bioorthogonal labeling strategy is the ability of native or engineered enzymes to accept these functionalized chemical reporters. This two-step approach allows the visualization and biochemical analysis of endogenous biomolecules that provides several important advantages for biological studies. First, the separation of metabolic or enzymatic incorporation and detection decouples sterically-demanding fluorophores or affinity tags that often interfere with biological activity from chemical reporters. Second, in comparison to protein-based reagents (e.g. antibodies), chemical reporters provide direct detection of the modified substrates and are relatively independent of adjacent functional groups, which may confound the specificity of protein reagents. Lastly, the ability to pulse-label specific populations of molecules in cells with chemical reporters provides an important means to monitor dynamics akin to classic radioactive tracers, but enables more sensitive detection and allows the direct identification of labeled targets. Since newly synthesized molecules can be separated from the steady state population in this manner, chemical reporters are excellent tools for monitoring the dynamics of biomolecules. The diversity of modifications on proteins and nucleic acids makes it difficult to track specific subsets independently. Therefore, specific chemical reporters provide important reagents to isolate distinct populations of biomolecules away from the vast chemical complexity of the cell. Bioorthogonal chemistry has also facilitated the analysis of small molecule interactions with proteins for biochemical target identification and activity-based protein profiling of chemical probes, which is beyond the scope of this review and is summarized elsewhere ${ }^{3}$. Herein we review the currently available chemical reporters and highlight how they can be applied to monitor temporal changes in cellular activity (Fig. 2a), profile different cell types, states or mutations (Fig. 2b) and identify targets of specific enzymes (Fig. 2c). We close with an outlook on the future challenges and developments that should expand the utility of bioorthogonal chemical reporters to even more complex biological settings in vivo.

\section{Chemical reporters for nucleic acids}

Gene expression arrays and deep-sequencing methods provide important profiles of steady state DNA and RNA expression, but understanding the rate of nucleic acid synthesis, degradation and modifications is crucial for elucidating their function in different biological contexts. The modification of nucleosides with alkynes has afforded chemical reporters of DNA and RNA synthesis. For example, 5-ethynyl-2'-deoxyuridine (EdU) ${ }^{4}$ and 5ethynyluridine $(\mathrm{EU})^{5}$ can be metabolized by mammalian cells and incorporated into DNA and RNA for bioorthogonal detection and pulse-chase experiments, respectively (Fig. 3a,b). These nucleic acid reporters function in animals and provide sensitive reagents to compare DNA and RNA turnover in different tissues using fluorescence. A fluorinated arabinosylEdU reporter has also been developed to improve the sensitivity of DNA labeling with reduced cytotoxicity compared to EdU (Fig. 3c) ${ }^{6}$. In addition to uridine derivatives, 5ethynyl-2'-deoxycytosine $(\mathrm{EdC})^{7}$ and N-6-propargyladenosine $(\mathrm{N} 6 \mathrm{pA})^{8}$ can be utilized by mammalian cells to label DNA and RNA, respectively (Fig. 3d,e). N6pA labeling also allows the pulse-chase analysis of RNA polyadenylation ${ }^{8}$. More recently, Raman spectroscopy has been employed to directly image EdU labeling of DNA in mammalian cells by taking advantage of the unique vibrational signature of alkynes ${ }^{9}$. To analyze nucleic acid modifications, a specific glycosyltransferase can be used to install 6-azido-glucose onto 5-hydroxymethylcytosine (5-hmc) marks in DNA for subsequent bioorthogonal detection (Fig. 3f $)^{10}$. This chemoenzymatic detection of 5-hmc has provided a particularly important 
method for characterizing the mechanism of DNA oxidation and demethylation catalyzed by Tet1-3 enzymes in eukaryotic cells ${ }^{11,12}$. These studies highlight the utility of chemical reporters for analyzing nucleic acid turnover and modifications that should facilitate future studies on epigenetic mechanisms.

\section{Chemical reporters for protein turnover}

Azide- and alkyne-bearing amino acids allow the co-translational labeling of newly synthesized proteins and provide a direct measure of the translational activity in cells (Fig. 4). Two strategies for non-canonical amino acid incorporation have been developed that enable site-specific or residue-selective labeling of proteins. The site-specific approach allows the incorporation of a non-canonical amino acid at a predetermined position in a protein of interest using amber suppression ${ }^{13}$. This method is based on engineering an orthogonal triad of tRNA, aminoacyl-tRNA-synthetase (aaRS) and non-canonical amino acid, which allows the site-specific installation of designer amino acids on individual proteins in bacteria, yeast and mammalian cells ${ }^{13}$ as well as whole animals such as worms ${ }^{14}$ and flies ${ }^{15}$. For example, the pyrrolysine (Pyl) system has enabled site-specific incorporation of amino acid reporters such as trans-cyclooctene-Lys or BCN-Lys into mammalian cells for fluorescence imaging of proteins after Diels-Alder ligation with tetrazine-functionalized dyes in living cells (Fig. 4a) ${ }^{16}$. Alternatively, azide and alkyne amino acids such as azidohomoalanine (AHA) and homopropargylglycine (HPG) can replace methionine (Met) for residue-selective incorporation into newly synthesized proteins (Fig. 4b) ${ }^{17}$. AHA and HPG are readily taken up and utilized by the wild type methionyltRNA-synthetase (metRS) in prokaryotic and eukaryotic cells, enabling the analysis of newly synthesized proteins by bioorthogonal labeling with fluorescence and affinity probes ${ }^{17}$. The availability of two uniquely reactive orientations (azide versus alkyne) also makes it possible to label and visualize two distinct protein populations with AHA and HPG, respectively ${ }^{17}$. In contrast to metabolic labeling with isotopically labeled amino acids, AHA and HPG labeled proteins can be bioorthogonally reacted with affinity tags and selectively recovered from total cell lysates for mass spectrometry-based protein identification. In addition, O-propargyl-puromycin (OP-puro) (Fig. 4c), an alkyne analog of the covalent translational inhibitor puromycin, can be used to label nascent polypeptide chains in mammalian cell culture as well as in mice ${ }^{18}$. In contrast to chemical reporters that are based on amino acid frequency, one OP-puro is attached to each nascent polypeptide, which could facilitate comparative studies of protein synthesis rates in the future.

The ability to differentiate newly synthesized proteins from pre-existing proteins with AHA or HPG has already begun to reveal important biological insights. For example, AHA pulse labeling can be used to enrich newly synthesized nucleosomes ${ }^{19}$. Nucleosome turnover potentially erases histone marks and serves as an important epigenetic mechanism. However, previous studies measured histone H3.3 incorporation as a surrogate for nucleosome turnover or used overexpressed histone transgenes to follow nucleosome dynamics. In contrast, AHA allows pulse labeling of endogenous histones and provides an affinity handle for enrichment and subsequent analysis of nucleosome-associated DNA ${ }^{19}$. This approach, termed CATCH-IT, provides better temporal resolution compared to previous histone replacement methods and has revealed more rapid turnover of nucleosomes at active genes, specific epigenetic marks, and replication origins ${ }^{19}$. AHA labeling also provides a useful means to differentiate secreted proteins from abundant proteins in serum, which in combination with stable isotope labeling with amino acids in cell culture (SILAC) has enabled quantitative analysis of mammalian secretomes ${ }^{20}$. The union of AHA labeling and SILAC has also facilitate the global analysis of newly synthesized proteins during T cell activation ${ }^{21}$. Spatial and dynamic regulation of protein synthesis is also particularly important in neurons, as localized translation is believed to shape axon growth, guidance and 
regeneration in the brain for synaptic plasticity and memory. To explore local translation in neurons, AHA and HPG labeling can be used to visualize specific sites and measure rates of protein synthesis in primary neurons after bioorthogonal labeling with fluorescent dyes and quantum dots ${ }^{22}$. Another application of AHA labeling in primary neuronal cultures revealed localized protein synthesis adjacent to the transmembrane receptor $\mathrm{DCC}^{23}$. These studies show how bioorthogonal amino acid reporters provide valuable tools for monitoring discrete protein populations and imaging protein synthesis at high resolution.

\section{Cell-selective labeling of proteomes}

Studying cells in their native environment and interaction with other cell types is crucial in many areas of biology. Methods for cell-selective proteome labeling would therefore be valuable for dissecting the activity of individual cells in heterogeneous populations. While AHA and HPG do not provide a means to separate proteomes of individual cell types, metRS mutants (metRS*) can facilitate the incorporation of the otherwise translationally inactive amino acid reporters such as azidonorleucine (ANL) ${ }^{17,24}$. Since ANL incorporation is dependent on metRS* activity, ANL can be selectively directed to certain cell types by expression of metRS ${ }^{* 24}$. For example, bacterial cells expressing metRS* can be selectively labeled with ANL in the presence of mammalian cells ${ }^{24}$. To differentiate bacterial proteins from host proteins during infection, 2-aminooctynoic acid (AOA), can also be activated by metRS* to selectively label the Gram-negative bacterial pathogen Salmonella typhimurium inside macrophages ${ }^{25}$. Notably, AOA enabled the proteomic analysis of S. typhimurium proteins that are differential expressed during infection of host cells ${ }^{25}$. In addition to these Met reporters, an alkyne phenylalanine (Phe) analog, para-ethynylphenylalanine (PEP) can also function as a cell-selective amino acid reporter in combination with a phenylalaninetRNA-synthetase mutant (A294G of pheS ${ }^{26}$. Amino acids such as Phe are present in higher frequencies than Met and the possible combination of these reporters may allow greater coverage of proteomes or even selective labeling of two different proteomes. These proteome selective labeling systems should facilitate the discovery and characterization of bacterial proteins that are uniquely expressed or secreted in mixed microbial communities like biofilms and host-microbe interactions. An extension of these strategies to eukaryotic systems might also allow selective labeling of individual cell types in multicellular organisms in the future.

\section{Chemical reporters for posttranslational modifications}

Chemical reporters have also been developed for diverse protein modifications in bacteria and eukaryotes. Since protein modifications can be sub-stoichiometric, dynamically regulated and further elaborated, these biomolecules can be especially difficult to analyze.

\section{Glycosylation}

The covalent attachment of glycans to proteins is one of the most ubiquitous and complex forms of protein modification in biology. Glycans decorate the exterior of eukaryotic cells and mediate a wide range of interactions with soluble extracellular factors, neighboring cells and microbes. Additionally, glycosylation plays an important role inside cells by regulating protein trafficking, turnover and signal transduction. Indeed, the complex roles of glycans and the challenges associated with their detection was a major driving force for the development of the Staudinger ligation (Fig. 1b) and the first azide-glycan reporter, Nazidoacetyl-D-mannosamine (ManNAz, Fig. 5a), for sialic acid biosynthesis ${ }^{27}$. This landmark study has inspired the development of many other azide- and alkynefunctionalized chemical reporters, including monosaccharide reporters for mucin-type Olinked glycoproteins (Fig. 5b), fucosylated glycans (Fig. 5c), and intracellular O-GlcNAc modified proteins (Fig. 5d), which have improved the biochemical detection and imaging of 
these glycans ${ }^{28}$. The metabolic incorporation of chemical reporters into cell surface glycans can also be used to select cell populations with aberrant glycosylation levels ${ }^{29}$. An early example of this strategy using a ketone-functionalized sialic acid precursor and hydrazide labeling revealed mutations in glycan biosynthetic enzymes associated with congenital human diseases such as sialuria ${ }^{29}$. Furthermore, these glycan reporters in combination with activated cyclooctyne probes have now enabled the dynamic imaging of cell surface glycans in live developing zebrafish embryos and in worms ${ }^{30}$, which opens the door for differential analysis of glycan biosynthesis in specific tissues and cell types in vivo. Glycan chemical reporters have also been incorporated into bacteria ${ }^{31-33}$ as well as plants ${ }^{34}$ that should afford new tools for functional studies in these organisms.

Metabolic and chemoenzymatic chemical reporters are providing new insight into OGlcNAc modification of cytoplasmic and nuclear proteins. O-GlcNAcylation of serine (Ser) and threonine (Thr) residues is dynamic and regulated form of intracellular glycosylation that is emerging as an important indicator of cellular metabolism and stress in diseases such as diabetes, neurodegeneration and cancer ${ }^{35}$. Initial studies demonstrated that $\mathrm{N}$-azidoacetylD-glucosamine (GlcNAz) could be utilized by the hexosamine salvage pathway and incorporated into O-GlcNAc modified proteins in mammalian cells ${ }^{36}$. More recently, an alkyne-modified GlcNAc analog (GlcNAlk, Fig. 5d) has enabled more sensitive bioorthogonal detection as well as greater proteomic coverage of O-GlcNAcylation and revealed glycosylation of the ubiquitin ligases such as NEDD4 ${ }^{37}$. Alternatively, O-GlcNAcmodified proteins in tissue/cell lysates can also be detected using a chemoenzymatic method using a ketone or azide-bearing sugar nucleotide reporter in conjunction with an engineered $\beta-1,4$-galactosyltransferase in vitro (Fig. $5 \mathrm{e})^{38}$. The enzymatically tagged O-GlcNAcmodified proteins can be evaluated by fluorescence, mass-shift western blotting and quantitative proteomics after bioorthogonal labeling ${ }^{38}$. This method has revealed both differential dynamics of O-GlcNAcylation in mammalian cells ${ }^{39}$ and O-GlcNAc regulation of CREB-mediated gene expression in neurons ${ }^{40}$. Azide- and alkyne-sugar nucleotide reporters have also been useful for in vitro profiling other glycosyltransferase substrate specificities ${ }^{41}$ as well as in vivo imaging of glycans ${ }^{42}$. These studies showcase the utility of chemical reporters for monitoring glycan biosynthesis, glycoproteomics and even imaging of glycans in vivo.

\section{Lipidation}

Lipid modifications of proteins modulate their membrane affinity, localization and trafficking for cell signaling ${ }^{43}$. Even though some forms of protein lipidation can now be predicted based on conserved amino acid motifs ${ }^{43}$, direct biochemical detection of lipidated proteins is still required for functional studies and discovery of unannotated substrates in different cell types and physiological states. As specific antibodies for lipid modifications have been difficult to generate, bioorthogonal chemical reporters have been especially valuable for the detection, discovery and characterization of lipidated proteins and their regulatory mechanisms ${ }^{44}$.

Protein S-prenylation is a prominent form of lipidation in mammalian cells that encompasses S-farnesylation or geranylgeranylation of cysteine (Cys) residues on CaaX or $\mathrm{CC}$ motifs, respectively ${ }^{43}$. These isoprenoid modifications typically occur at the $\mathrm{C}$-terminus of proteins such as small GTPases and is crucial for their membrane targeting and activity in cells $^{43}$. To improve biochemical analysis of protein S-prenylation, azide ${ }^{45}$ and alkyne ${ }^{46,47}$ isoprenoid reporters have been developed that allow more sensitive bioorthogonal detection and enrichment of S-prenylated proteins in mammalian cells. Indeed, proteomic analysis of alkynyl-farnesol (alk-FOH) (Fig. 6c or Fig. 6 - is fine with me) modified proteins in macrophages has enabled large-scale profiling of known and unpredicted S-prenylated 
proteins and revealed that isoform-specific $S$-farnesylation is crucial for the membrane targeting and antiviral activity of zinc-finger antiviral protein $(\mathrm{ZAP})^{48}$.

Azide and alkyne fatty acids can also be used to monitor fatty-acylated substrates in bacteria and eukaryotes ${ }^{44}$. Myristoylation of $\mathrm{N}$-terminal glycine (Gly) residues by $\mathrm{N}$ myristoyltransferases (NMTs) occurs primarily cotranslationally and is readily labeled by myristic acid reporters in mammalian cells (Fig. 6a) ${ }^{43}$. Interestingly, the application of Nmyristoylation reporter labeling has revealed a unique proteolytic activity of a secreted bacterial effector IpaJ on N-myristoylated host proteins that contributes to the virulence of bacterial pathogen Shigella flexneri ${ }^{49}$. In contrast to N-terminal myristoylation, Spalmitoylation of Cys residues is not readily predicted by primary amino acid sequence, can be reversible, regulated by a family of palmitoyltransferases with the conserved Asp-HisHis-Cys-motif (DHHC-PATs) and thus particularly challenging to analyze biochemically ${ }^{50}$. Metabolic labeling with alkyne fatty acid reporters (Fig. 6b) in combination with bioorthogonal detection has largely solved this problem, enabling rapid visualization and proteomic analysis of S-palmitoylated proteins ${ }^{44}$. Notably, bioorthogonal palmitoylome profiling has increased the diversity of S-palmitoylated proteins in mammalian cells ${ }^{51-54}$ and even revealed new fatty-acylated proteins such as IFITM3 in innate immunity ${ }^{53}$. Fatty acid reporters have also been especially useful for monitoring protein S-palmitoylation dynamics. For example, tandem pulse-chase labeling of T cells with protein synthesis and palmitoylation reporters provides a robust method for quantifying S-acylation dynamics relative to protein turnover 55 . The application of this method revealed accelerated depalmitoylation of signaling kinases such as Lck upon $\mathrm{T}$ cell activation ${ }^{55}$. In addition, the large-scale analysis of S-palmitoylation dynamics using bioorthogonal labeling and SILAC showed that many proteins are stably fatty-acylated while other proteins involved in cell signaling undergo rapid S-acylation cycles ${ }^{56}$. The application of fatty acid reporters to model systems such as Schizosaccharomyces pombe (fission yeast) has also afforded new opportunities to investigate S-palmitoylation mechanisms ${ }^{57}$. Palmitoylome profiling of wild type $S$. pombe and DHHC-PAT deletion strains and additional functional studies has revealed that quantitative expression levels of a single DHHC-PAT can control Spalmitoylation of specific protein substrates and help drive major cellular transitions such as meiotic entry in fission yeast ${ }^{57}$. In addition cytoplasmic proteins, secreted proteins are also lipid-modified and readily labeled by chemical reporters as highlighted by fatty acid and cholesterol reporter labeling of $\mathrm{Wnt}^{58}$ and sonic hedgehog proteins (Fig. 6d) ${ }^{59}$, respectively. In vitro biochemical studies and fatty acid reporter labeling experiments in mammalian cells has also shown that long chain-fatty acylation of Lys side chains can be removed by Sirt6, a sirtuin-family deacylase previously thought to function only acetylated Lys ${ }^{60}$, and modulate the secretion of proinflammatory cytokines such as TNF-a. These chemical reporters can also be used monitoring the lipid metabolism and trafficking in mammalian cells ${ }^{61-64}$. As lipids can be difficult to tag and purify, these challenges have motivated the development of substituted cyclopropenes as another small bioorthogonal $\operatorname{tag}^{62}$ and the application cobaltaffinity matrices for the capture and enrichment of alkynyl-lipids ${ }^{63}$.

Lipid reporters also allow labeling of bacterial proteins ${ }^{65}$. Protein lipidation in bacteria involves the installation of a diacylglyceryl group onto $\mathrm{N}$-terminal Cys residue within a well-defined lipobox-motif ${ }^{66}$. Although algorithms are available for the prediction of canonical bacterial lipoproteins ${ }^{66}$, many lipidated proteins in bacteria are poorly characterized and may exist in other forms. In this regard, the application of fatty acid reporters to bacteria allows both the rapid profiling of canonical bacterial lipoproteins as well as the discovery of unconventionally lipidated proteins in bacteria ${ }^{65}$. These applications of bioorthogonal lipid reporters are thus revealing new fatty-acylated proteins and their mechanisms of regulation in variety important biological systems. 


\section{Acylation}

The acylation of Lys residues plays important roles in epigenetic regulation of transcription, signaling and metabolism ${ }^{67}$. With the increase of Lys acetylated proteins from recent proteomic studies in mammalian cells and bacteria ${ }^{67}$, characterizing what substrates are regulated by specific Lys acetyltransferases (KATs) and deacetylases (KDACs) in various signaling pathways is a major challenge. In this regard, alkyne analogs of acetate and acetylCoA such as sodium 4-pentynoate and 4-pentynoyl-CoA can function as chemical reporters of Lys acetylation in cells and in vitro, respectively (Fig. 7a). Metabolic labeling of mammalian cells with 4-pentynoate readily labels known Lys acetylated proteins such as histones and allows simple fluorescence profiling of acetylated proteins in different cell types ${ }^{68}$. In addition, 4-pentynoyl-CoA is utilized by the KAT $\mathrm{p} 300$ for in vitro bioorthogonal profiling of candidate protein substrates in cell lysates ${ }^{69}$. As acetylation also occurs on the N-terminus of proteins ${ }^{70}$ and Ser/Thr residues ${ }^{71}$, acetylation reporters should also facilitate the analysis of these modifications. Other forms of Lys acylation such as propionylation, butyrylation, malonylation, succinylation and crotonylation have also been recently described ${ }^{67}$, which may also benefit from specific bioorthogonal reporters to characterize labeled proteins and activity of regulatory enzymes. Indeed, a chemical reporter for protein malonylation has been recently reported ${ }^{72}$.

\section{Methylation}

The modification of Lys or arginine (Arg) residues with one or more methyl groups are important posttranslational modifications in chromatin biology and other cellular pathways ${ }^{73}$. The general cofactor for most cellular methylation reactions is S-adenosyl-Lmethionine (SAM), from which the methyl group is transferred onto proteins, nucleic acids or other substrates. The development of bioorthogonal methylation reporters has therefore attracted considerable interest. Initial studies demonstrated that DNA methyltransferases were able to transfer allylic or propargylic groups from SAM reporters onto DNA substrates ${ }^{74}$. AdoEnYn (Fig. 7b) was then developed as a SAM reporter for site-selective labeling of protein methyltransferase substrates such as histone $\mathrm{H} 3{ }^{75}$. Lys methyltransferase mutants that can utilize (E)-hex-2-en-5-ynyl-SAM (Hey-SAM) have also been described for bioorthogonal profiling of protein methylation ${ }^{76}$. In addition to Lys methyltransferases, a double mutant of protein Arg methyltransferase PRMT1 can utilize 4-propargyloxy-but-2enyl-SAM (Pob-SAM) and label potential target proteins in cell lysates ${ }^{77}$. Interestingly, the expression of engineered SAM synthetase and methyltransferase capable of utilizing an alkynyl-Met reporter in mammalian cells has allowed metabolic labeling of histones and subsequent click chemistry-based chromatin enrichment and parallel DNA sequencing ${ }^{78}$. While thiol-based SAM reporters are functional, these reagents can be unstable and nonspecifically label substrates. To address this limitation, a selenium-based SAM reporter has been developed that is more stable and can be readily utilized by both Lys and Arg methyltransferases in vitro ${ }^{79,80}$. Improved methylation chemical reporters in combination with bioorthogonal enrichment methods should facilitate the identification of specific methyltransferase substrates in the future.

\section{ADP-Ribosylation}

Proteins can be modified with mono- and poly-ADP-ribose on a range of different residues ${ }^{81}$. This modification was initially described as the virulence mechanism for a number of different bacterial toxins, but it is now appreciated as a prevalent protein modification in eukaryotes as well ${ }^{81}$. Mono-ADP-ribosylation is carried out by a set of mono-ADP-ribosyltransferases (MARTs) that utilize the cofactor nicotinamide adenine dinucleotide (NAD), from which the ADP-ribose moiety is transferred onto the protein substrate. In eukaryotes, the mono-ADP-ribose modification can be extended by poly-ADP- 
ribosylpolymerases (PARPs) to form poly-ADP-ribosylated proteins. The growing list of ADP-ribosylation substrates has motivated the development of chemical reporters to characterize the specificity and functions of the PARPs ${ }^{82}$. For example, 8-alkyne-NAD and 6-alkyne-NAD (Fig. 7c) can function as chemical reporters for diphteria toxin (DT), a wellcharacterized MART that modifies elongation factor eEF- $2^{82}$. The analysis of these chemical reporters with PARP-1 and Tankyrase-1, revealed that 6-alkyne-NAD was most effective for monitoring the ADP-ribosylation of p53 and TRF-1 ${ }^{82}$. Incubation of cell lysates with recombinant PARP-1 and 6-alkyne-NAD enabled bioorthogonal detection and enrichment of poly-ADP-ribosylated proteins, demonstrating the utility of these reagents for ADP-ribosylation analysis.

\section{AMPylation}

Though originally discovered in the context of glutamine synthetase regulation in E. coli, AMPylation (adenylylation) has become more widely appreciated since the discovery of secreted bacterial effector enzymes that modify host small GTPases during infection ${ }^{83}$. AMPylation describes the enzymatic transfer of an adenosine monophosphate (AMP) from ATP onto hydroxyl protein side chains. The conserved protein domains (fic domain, adenylyl transferase domain) responsible for the AMPylation activity are widely present among prokaryotes and eukaryotes, suggesting a ubiquitous role for this $\mathrm{PTM}^{84}$. Recent studies have also revealed specific phosphoesterases that can remove the AMP moiety, suggesting that this modification can be dynamic and regulated ${ }^{85,86}$. The re-emergence and abundance of potential AMPylation enzymes has motivated the development of specific antibodies, mass spectrometry detection methods as well as an AMPylation reporter ${ }^{87}$. Modification of ATP at the $\mathrm{N}^{6}$-position with a propargyl group provides an alkynedecorated AMPylation reporter ( $\mathrm{N}^{6}$ pATP) (Fig. 7 d) that can be enzymatically transferred onto specific sites of cognate protein substrates by all known classes of AMPylation enzymes ${ }^{87}$. Furthermore, $\mathrm{N}^{6} \mathrm{pATP}$ can be used to identify AMPylation substrates at endogenous levels in cell lysates ${ }^{87}$, which should facilitate the characterization of AMPylated proteins in diverse organisms.

\section{Phosphorylation}

The reversible addition of phosphate onto Ser, Thr or tyrosine (Tyr) residues on proteins are perhaps the best studied PTMs for which specific antibodies and quantitative proteomic methods have been developed ${ }^{88}$. Nonetheless, the large number of phosphoproteins and regulatory enzymes (kinases and phosphatases) with potentially overlapping biochemical activity makes dissecting phosphorylation-dependent signaling pathways still very challenging. Robust biochemical methods for directly monitoring enzyme-specific phosphorylation events are needed. The development of adenosine triphosphate (ATP) analogs and complementary kinase mutants has allowed the direct identification of enzymespecific protein substrates ${ }^{89}$. To distinguish kinase-specific phosphorylation events from existing phosphoproteins in cell lysates, $\mathrm{N}^{6}$ benzyl-ATP $\gamma \mathrm{S}$ and mutant kinases were employed to selectively phosphorylate specific protein substrates ${ }^{90}$. The enzymatically installed phosphorothiolate group could then be selectively alkylated with a nitrobenzylhapten to yield a semisynthetic epitope for antibody-based detection (Fig. 7e) ${ }^{90}$ or covalently captured and oxidatively cleaved ${ }^{91}$ for identification of kinase-specific substrates. Although this system does not utilize alkyne- or azide-functionalized reagents, this two-step labeling protocol is itself bioorthogonal and showcases the utility of bump-hole approaches for identifying enzyme-specific substrates in systems with overlapping biochemical activity. 


\section{Oxidation}

The oxidation of amino acid side chains can result in significant rearrangements of protein structure as in the case of the green fluorescent protein (GFP) or more subtle changes such as hydroxylation of amino acid residues. These subtle PTMs are perhaps the most challenging for bioorthogonal labeling approaches. Nonetheless, specific chemical reagents have been identified that enable bioorthogonal detection of some protein oxidation reactions. For example, the functionalization of dimedone with an alkyne enabled the selective labeling of sulfenic acid modified proteins in cells and subsequent bioorthogonal detection and proteomic analysis (Fig. 7f) ${ }^{92}$. Interestingly, stimulation of the epidermal growth factor receptor (EGFR) results in elevated hydrogen peroxide levels which in turn oxidizes Cys797 of EGFR to enhance its tyrosine kinase activity ${ }^{92}$. These observations suggest an interesting positive feedback loop to amplify EGFR-dependent signaling ${ }^{92}$. By taking advantage of unique chemical reactivity, bioorthogonal reporters can be developed for specific forms of protein oxidation and reveal previously unappreciated mechanisms of cell signaling.

\section{Summary and Future Outlook}

Bioorthogonal chemical reporters are providing powerful tools to track biomolecules in living systems and are illuminating new aspects of biology. While the past decade has seen significant progress in bioorthogonal reactions (Fig. 1) ${ }^{1,2}$ and specific chemical reporters highlighted here, major advances are still needed to dissect complex biological systems with these chemical tools. Amongst the currently available bioorthogonal ligation reactions (Fig. 1), no single method is ideal for all imaging and proteomic applications. So researchers need to choose the labeling method and reagents that best suits their biological interests. For example, CuAAC with biotinylated affinity tags have been highly effective for bioorthogonal proteomic studies with cell lysates, but not ideal for live cell imaging studies due to potential metal toxicity. Metal-free ligation methods are beginning to address the challenges of live intracellular and in vivo imaging applications ${ }^{2,93,94}$, but more selective bioorthogonal reactions are still needed that can integrate membrane-permeable imaging reagents with bright fluorogenic properties and minimal non-specific binding. The development of sensitive imaging methods that target unique spectroscopic signatures of chemical reporters or isotopic labels should also provide new opportunities for in vivo imaging studies 9,95 . On the chemical reporter end, a better understanding of metabolism or interconversion of chemical reporters in vivo is necessary to fully understand what biological events these reagents actually report upon. As with protein tagging technologies, the modification of cellular metabolites with reactive groups could interfere with their metabolism, the activity of intermediate enzymes, or the function of labeled substrates. More detailed analyses of chemical reporter metabolism and protein targets is therefore needed, which may in turn yield more specific reagents to selectively monitor key enzymatic pathways and also avoid potential perturbation of native signaling pathways. Many of the cofactor-based reporters only work with some enzymes and would benefit from engineered enzymes for in vitro activity studies, and the development of caged precursors for experiments in living cells. The integration of selective targeting methods such as enzymemediated uncaging ${ }^{96}$ or liposome delivery ${ }^{97}$ should also facilitate the cell-type specific analysis of chemical reporters in vivo. These two-component systems for bioorthogonal chemical reporters could then be used in vivo for enzyme- or cell-specific imaging and proteomics studies. By virtue of their specific and dynamic incorporation into biomolecules, chemical reporters can provide snapshots of the chemistry inside cells that integrates the activity of metabolic pathways and specific enzymes for functional studies. Further developments and applications of bioorthogonal labeling methods and chemical reporters should help translate the information encoded in the growing number of sequenced genomes 
into biological function and begin to uncover key mechanisms of human diseases for therapeutic intervention.

\section{Acknowledgments}

We thank Kavita Rangan and Nathan Westcott for helpful comments on the manuscript. H.C.H. acknowledges support from Ellison Medical Foundation and NIH/NIGMS (1R01GM087544).

\section{References}

1. Prescher JA, Bertozzi CR. Chemistry in living systems. Nat Chem Biol. 2005; 1:13-21. [PubMed: 16407987]

2. Sletten EM, Bertozzi CR. From mechanism to mouse: a tale of two bioorthogonal reactions. Acc Chem Res. 2011; 44:666-676. [PubMed: 21838330]

3. Nomura DK, Dix MM, Cravatt BF. Activity-based protein profiling for biochemical pathway discovery in cancer. Nat Rev Cancer. 2010; 10:630-638. [PubMed: 20703252]

4. Salic A, Mitchison TJ. A chemical method for fast and sensitive detection of DNA synthesis in vivo. Proc Natl Acad Sci U S A. 2008; 105:2415-2420. [PubMed: 18272492]

5. Jao CY, Salic A. Exploring RNA transcription and turnover in vivo by using click chemistry. Proc Natl Acad Sci U S A. 2008; 105:15779-157784. [PubMed: 18840688]

6. Neef AB, Luedtke NW. Dynamic metabolic labeling of DNA in vivo with arabinosyl nucleosides. Proc Natl Acad Sci U S A. 2011; 108:20404-20409. [PubMed: 22143759]

7. Guan L, van der Heijden GW, Bortvin A, Greenberg MM. Intracellular detection of cytosine incorporation in genomic DNA by using 5-ethynyl-2'-deoxycytidine. Chembiochem. 2011; 12:2184-2190. [PubMed: 21805552]

8. Grammel M, Hang H, Conrad NK. Chemical reporters for monitoring RNA synthesis and poly(A) tail dynamics. Chembiochem. 2012; 13:1112-1115. [PubMed: 22513998]

9. Yamakoshi H, et al. Imaging of EdU, an Alkyne-Tagged Cell Proliferation Probe, by Raman Microscopy. J Am Chem Soc. 2011

10. Song CX, et al. Selective chemical labeling reveals the genome-wide distribution of 5hydroxymethylcytosine. Nat Biotechnol. 2011; 29:68-72. [PubMed: 21151123]

11. He YF, et al. Tet-mediated formation of 5-carboxylcytosine and its excision by TDG in mammalian DNA. Science. 2011; 333:1303-1307. [PubMed: 21817016]

12. Ito $\mathrm{S}$, et al. Tet proteins can convert 5-methylcytosine to 5-formylcytosine and 5-carboxylcytosine. Science. 2011; 333:1300-1303. [PubMed: 21778364]

13. Liu CC, Schultz PG. Adding new chemistries to the genetic code. Annu Rev Biochem. 2010; 79:413-444. [PubMed: 20307192]

14. Greiss S, Chin JW. Expanding the genetic code of an animal. J Am Chem Soc. 2011; 133:1419614199. [PubMed: 21819153]

15. Bianco A, Townsley FM, Greiss S, Lang K, Chin JW. Expanding the genetic code of Drosophila melanogaster. Nat Chem Biol. 2012; 8:748-750. [PubMed: 22864544]

16. Lang K, et al. Genetic Encoding of Bicyclononynes and trans-Cyclooctenes for Site-Specific Protein Labeling in Vitro and in Live Mammalian Cells via Rapid Fluorogenic Diels-Alder Reactions. J Am Chem Soc. 2012; 134:10317-10320. [PubMed: 22694658]

17. Johnson JA, Lu YY, Van Deventer JA, Tirrell DA. Residue-specific incorporation of noncanonical amino acids into proteins: recent developments and applications. Curr Opin Chem Biol. 2010; 14:774-780. [PubMed: 21071259]

18. Liu J, Xu Y, Stoleru D, Salic A. Imaging protein synthesis in cells and tissues with an alkyne analog of puromycin. Proc Natl Acad Sci U S A. 2012; 109:413-418. [PubMed: 22160674]

19. Deal RB, Henikoff JG, Henikoff S. Genome-wide kinetics of nucleosome turnover determined by metabolic labeling of histones. Science. 2010; 328:1161-1164. [PubMed: 20508129]

20. Eichelbaum K, Winter M, Diaz MB, Herzig S, Krijgsveld J. Selective enrichment of newly synthesized proteins for quantitative secretome analysis. Nat Biotechnol. 2012; 30:984-990. [PubMed: 23000932] 
21. Howden AJ, et al. QuaNCAT: quantitating proteome dynamics in primary cells. Nat Methods. 2013; 10:343-346. [PubMed: 23474466]

22. Dieterich DC, et al. In situ visualization and dynamics of newly synthesized proteins in rat hippocampal neurons. Nat Neurosci. 2010; 13:897-905. [PubMed: 20543841]

23. Tcherkezian J, Brittis PA, Thomas F, Roux PP, Flanagan JG. Transmembrane receptor DCC associates with protein synthesis machinery and regulates translation. Cell. 2010; 141:632-644. [PubMed: 20434207]

24. Ngo JT, et al. Cell-selective metabolic labeling of proteins. Nat Chem Biol. 2009; 5:715-717. [PubMed: 19668194]

25. Grammel M, Zhang MM, Hang HC. Orthogonal alkynyl amino acid reporter for selective labeling of bacterial proteomes during infection. Angew Chem Int Ed Engl. 2010; 49:5970-5974. [PubMed: 20632346]

26. Grammel M, Dossa PD, Taylor-Salmon E, Hang HC. Cell-selective labeling of bacterial proteomes with an orthogonal phenylalanine amino acid reporter. Chem Commun (Camb). 2012; 48:14731474. [PubMed: 22080199]

27. Saxon E, Bertozzi CR. Cell surface engineering by a modified Staudinger reaction. Science. 2000; 287:2007-2010. [PubMed: 10720325]

28. Laughlin ST, Bertozzi CR. Imaging the glycome. Proc Natl Acad Sci U S A. 2009; 106:12-17. [PubMed: 19104067]

29. Yarema KJ, Goon S, Bertozzi CR. Metabolic selection of glycosylation defects in human cells. Nat Biotechnol. 2001; 19:553-558. [PubMed: 11385460]

30. Laughlin ST, Baskin JM, Amacher SL, Bertozzi CR. In vivo imaging of membrane-associated glycans in developing zebrafish. Science. 2008; 320:664-667. [PubMed: 18451302]

31. Dumont A, Malleron A, Awwad M, Dukan S, Vauzeilles B. Click-mediated labeling of bacterial membranes through metabolic modification of the lipopolysaccharide inner core. Angew Chem Int Ed Engl. 2012; 51:3143-3146. [PubMed: 22323101]

32. Liu F, Aubry AJ, Schoenhofen IC, Logan SM, Tanner ME. The engineering of bacteria bearing azido-pseudaminic acid-modified flagella. Chembiochem. 2009; 10:1317-1320. [PubMed: 19422007]

33. Swarts BM, et al. Probing the mycobacterial trehalome with bioorthogonal chemistry. J Am Chem Soc. 2012; 134:16123-16126. [PubMed: 22978752]

34. Anderson CT, Wallace IS, Somerville CR. Metabolic click-labeling with a fucose analog reveals pectin delivery, architecture, and dynamics in Arabidopsis cell walls. Proc Natl Acad Sci U S A. 2012; 109:1329-1334. [PubMed: 22232683]

35. Hart GW, Slawson C, Ramirez-Correa G, Lagerlof O. Cross talk between O-GlcNAcylation and phosphorylation: roles in signaling, transcription, and chronic disease. Annu Rev Biochem. 2011; 80:825-858. [PubMed: 21391816]

36. Vocadlo DJ, Hang HC, Kim EJ, Hanover JA, Bertozzi CR. A chemical approach for identifying OGlcNAc-modified proteins in cells. Proc Natl Acad Sci U S A. 2003; 100:9116-9121. [PubMed: 12874386]

37. Zaro BW, Yang YY, Hang HC, Pratt MR. Chemical reporters for fluorescent detection and identification of O-GlcNAc-modified proteins reveal glycosylation of the ubiquitin ligase NEDD4-1. Proc Natl Acad Sci U S A. 2011; 108:8146-8151. [PubMed: 21540332]

38. Rexach JE, Clark PM, Hsieh-Wilson LC. Chemical approaches to understanding O-GlcNAc glycosylation in the brain. Nat Chem Biol. 2008; 4:97-106. [PubMed: 18202679]

39. Rexach JE, et al. Quantification of O-glycosylation stoichiometry and dynamics using resolvable mass tags. Nat Chem Biol. 2010; 6:645-651. [PubMed: 20657584]

40. Rexach JE, et al. Dynamic O-GlcNAc modification regulates CREB-mediated gene expression and memory formation. Nat Chem Biol. 2012; 8:253-261. [PubMed: 22267118]

41. Pratt MR, et al. Deconvoluting the functions of polypeptide N-alphaacetylgalactosaminyltransferase family members by glycopeptide substrate profiling. Chem Biol. 2004; 11:1009-1016. [PubMed: 15271359]

42. Zheng T, et al. Tracking N-acetyllactosamine on cell-surface glycans in vivo. Angew Chem Int Ed Engl. 2011; 50:4113-4118. [PubMed: 21472942] 
43. Resh MD. Trafficking and signaling by fatty-acylated and prenylated proteins. Nat Chem Biol. 2006; 2:584-590. [PubMed: 17051234]

44. Hang HC, Wilson JP, Charron G. Bioorthogonal chemical reporters for analyzing protein lipidation and lipid trafficking. Acc Chem Res. 2011; 44:699-708. [PubMed: 21675729]

45. Kho Y, et al. A tagging-via-substrate technology for detection and proteomics of farnesylated proteins. Proceedings of the National Academy of Sciences of the United States of America. 2004; 101:12479-12484. [PubMed: 15308774]

46. Charron G, Tsou LK, Maguire W, Yount JS, Hang HC. Alkynyl-farnesol reporters for detection of protein S-prenylation in cells. Mol Biosyst. 2011; 7:67-73. [PubMed: 21107478]

47. DeGraw AJ, et al. Evaluation of alkyne-modified isoprenoids as chemical reporters of protein prenylation. Chem Biol Drug Des. 2010; 76:460-471. [PubMed: 21040496]

48. Charron G, Li M, MacDonald M, Hang HC. Prenylome profiling reveals S-farnesylation is crucial for membrane targeting and antiviral activity of ZAP long-isoform. Proceedings of the National Academy of Sciences of the United States of America. 2013 in press.

49. Burnaevskiy N, et al. Proteolytic elimination of N-myristoyl modifications by the Shigella virulence factor IpaJ. Nature. 2013; 496:106-109. [PubMed: 23535599]

50. Fukata Y, Fukata M. Protein palmitoylation in neuronal development and synaptic plasticity. Nat Rev Neurosci. 2010; 11:161-175. [PubMed: 20168314]

51. Martin BR, Cravatt BF. Large-scale profiling of protein palmitoylation in mammalian cells. Nat Methods. 2009; 6:135-138. [PubMed: 19137006]

52. Wilson JP, Raghavan AS, Yang YY, Charron G, Hang HC. Proteomic analysis of fatty-acylated proteins in mammalian cells with chemical reporters reveals $\mathrm{S}$-acylation of histone $\mathrm{H} 3$ variants. Mol Cell Proteomics. 2011; 10 M110 001198.

53. Yount JS, et al. Palmitoylome profiling reveals S-palmitoylation-dependent antiviral activity of IFITM3. Nat Chem Biol. 2010; 6:610-614. [PubMed: 20601941]

54. Li Y, Martin BR, Cravatt BF, Hofmann SL. DHHC5 protein palmitoylates flotillin-2 and is rapidly degraded on induction of neuronal differentiation in cultured cells. J Biol Chem. 2012; 287:523530. [PubMed: 22081607]

55. Zhang MM, Tsou LK, Charron G, Raghavan AS, Hang HC. Tandem fluorescence imaging of dynamic S-acylation and protein turnover. Proc Natl Acad Sci U S A. 2010; 107:8627-8632. [PubMed: 20421494]

56. Martin BR, Wang C, Adibekian A, Tully SE, Cravatt BF. Global profiling of dynamic protein palmitoylation. Nat Methods. 2012; 9:84-89. [PubMed: 22056678]

57. Zhang M, Wu P-YJ, Kelly FD, Nurse P, Hang HC. Quantitative Control Protein S-Palmitoylation Regulates Meiotic Entry in Fission Yeast. PLoS Biol. 2013 in press.

58. Ching W, Hang HC, Nusse R. Lipid-independent secretion of a Drosophila Wnt protein. J Biol Chem. 2008; 283:17092-17098. [PubMed: 18430724]

59. Heal WP, et al. Bioorthogonal chemical tagging of protein cholesterylation in living cells. Chem Commun (Camb). 2011

60. Jiang H, et al. SIRT6 regulates TNF-alpha secretion through hydrolysis of long-chain fatty acyl lysine. Nature. 2013; 496:110-113. [PubMed: 23552949]

61. Jao CY, Roth M, Welti R, Salic A. Metabolic labeling and direct imaging of choline phospholipids in vivo. Proc Natl Acad Sci U S A. 2009; 106:15332-15337. [PubMed: 19706413]

62. Yang J, Seckute J, Cole CM, Devaraj NK. Live-Cell Imaging of Cyclopropene Tags with Fluorogenic Tetrazine Cycloadditions. Angew Chem Int Ed Engl. 2012

63. Milne SB, et al. Capture and release of alkyne-derivatized glycerophospholipids using cobalt chemistry. Nat Chem Biol. 2010; 6:205-207. [PubMed: 20098428]

64. Thiele C, et al. Tracing Fatty Acid Metabolism by Click Chemistry. ACS Chem Biol. 2012; 7:2004-2011. [PubMed: 22999348]

65. Rangan KJ, Yang YY, Charron G, Hang HC. Rapid visualization and large-scale profiling of bacterial lipoproteins with chemical reporters. J Am Chem Soc. 2010; 132:10628-10629.

[PubMed: 20230003] 
66. Babu MM, et al. A database of bacterial lipoproteins (DOLOP) with functional assignments to predicted lipoproteins. Journal of Bacteriology. 2006; 188:2761-2773. [PubMed: 16585737]

67. Lin H, Su X, He B. Protein lysine acylation and cysteine succination by intermediates of energy metabolism. ACS Chem Biol. 2012; 7:947-960. [PubMed: 22571489]

68. Yang YY, Ascano JM, Hang HC. Bioorthogonal chemical reporters for monitoring protein acetylation. J Am Chem Soc. 2010; 132:3640-3641. [PubMed: 20192265]

69. Yang YY, Grammel M, Hang HC. Identification of lysine acetyltransferase p300 substrates using 4-pentynoyl-coenzyme A and bioorthogonal proteomics. Bioorg Med Chem Lett. 2011; 21:49764979. [PubMed: 21669532]

70. Arnesen T, et al. Proteomics analyses reveal the evolutionary conservation and divergence of Nterminal acetyltransferases from yeast and humans. Proc Natl Acad Sci U S A. 2009; 106:81578162. [PubMed: 19420222]

71. Mukherjee S, Hao YH, Orth K. A newly discovered post-translational modification--the acetylation of serine and threonine residues. Trends Biochem Sci. 2007; 32:210-216. [PubMed: 17412595]

72. Bao X, Zhao Q, Yang T, Fung YM, Li XD. A chemical probe for lysine malonylation. Angew Chem Int Ed Engl. 2013; 52:4883-4886. [PubMed: 23533089]

73. Greer EL, Shi Y. Histone methylation: a dynamic mark in health, disease and inheritance. Nat Rev Genet. 2012; 13:343-357. [PubMed: 22473383]

74. Dalhoff C, Lukinavicius G, Klimasauskas S, Weinhold E. Direct transfer of extended groups from synthetic cofactors by DNA methyltransferases. Nat Chem Biol. 2006; 2:31-32. [PubMed: 16408089]

75. Peters W, et al. Enzymatic site-specific functionalization of protein methyltransferase substrates with alkynes for click labeling. Angew Chem Int Ed Engl. 2010; 49:5170-5173. [PubMed: 20572224]

76. Islam K, Zheng W, Yu H, Deng H, Luo M. Expanding cofactor repertoire of protein lysine methyltransferase for substrate labeling. ACS Chem Biol. 2011; 6:679-684. [PubMed: 21495674]

77. Wang R, Zheng W, Yu H, Deng H, Luo M. Labeling substrates of protein arginine methyltransferase with engineered enzymes and matched S-adenosyl-L-methionine analogues. J Am Chem Soc. 2011; 133:7648-7651. [PubMed: 21539310]

78. Wang R, et al. Profiling Genome-Wide Chromatin Methylation with Engineered Posttranslation Apparatus within Living Cells. J Am Chem Soc. 2013; 135:1048-1056. [PubMed: 23244065]

79. Willnow S, Martin M, Luscher B, Weinhold E. A Selenium-Based Click AdoMet Analogue for Versatile Substrate Labeling with Wild-Type Protein Methyltransferases. Chembiochem. 2012; 13:1167-1173. [PubMed: 22549896]

80. Bothwell I, et al. Se-adenosyl-L-selenomethionine cofactor analogue as a reporter of protein methylation. J. Am. Chem. Soc. 2012; 134:14905-14912. [PubMed: 22917021]

81. Gibson BA, Kraus WL. New insights into the molecular and cellular functions of poly(ADPribose) and PARPs. Nat Rev Mol Cell Biol. 2012; 13:411-424. [PubMed: 22713970]

82. Jiang H, Kim JH, Frizzell KM, Kraus WL, Lin H. Clickable NAD analogues for labeling substrate proteins of poly(ADP-ribose) polymerases. J Am Chem Soc. 2010; 132:9363-9372. [PubMed: 20560583]

83. Yarbrough ML, et al. AMPylation of Rho GTPases by Vibrio VopS disrupts effector binding and downstream signaling. Science. 2009; 323:269-272. [PubMed: 19039103]

84. Woolery AR, Luong P, Broberg CA, Orth K. AMPylation: Something Old is New Again. Front Microbiol. 2010; 1:113. [PubMed: 21607083]

85. Muller MP, et al. The Legionella effector protein DrrA AMPylates the membrane traffic regulator Rab1b. Science. 2010; 329:946-949. [PubMed: 20651120]

86. Tan Y, Luo ZQ. Legionella pneumophila SidD is a deAMPylase that modifies Rab1. Nature. 2011; 475:506-509. [PubMed: 21734656]

87. Grammel M, Luong P, Orth K, Hang HC. A chemical reporter for protein AMPylation. J Am Chem Soc. 2011; 133:17103-17105. [PubMed: 21942216] 
88. Macek B, Mann M, Olsen JV. Global and site-specific quantitative phosphoproteomics: principles and applications. Annu Rev Pharmacol Toxicol. 2009; 49:199-221. [PubMed: 18834307]

89. Shogren-Knaak MA, Alaimo PJ, Shokat KM. Recent advances in chemical approaches to the study of biological systems. Annu Rev Cell Dev Biol. 2001; 17:405-433. [PubMed: 11687495]

90. Allen JJ, et al. A semisynthetic epitope for kinase substrates. Nat Methods. 2007; 4:511-516. [PubMed: 17486086]

91. Blethrow JD, Glavy JS, Morgan DO, Shokat KM. Covalent capture of kinase-specific phosphopeptides reveals Cdk1-cyclin B substrates. Proc Natl Acad Sci U S A. 2008; 105:14421447. [PubMed: 18234856]

92. Paulsen CE, et al. Peroxide-dependent sulfenylation of the EGFR catalytic site enhances kinase activity. Nat Chem Biol. 2012; 8:57-64. [PubMed: 22158416]

93. Blackman ML, Royzen M, Fox JM. Tetrazine ligation: fast bioconjugation based on inverseelectron-demand Diels-Alder reactivity. J Am Chem Soc. 2008; 130:13518-13519. [PubMed: $18798613]$

94. Devaraj NK, Weissleder R. Biomedical applications of tetrazine cycloadditions. Acc Chem Res. 2011; 44:816-827. [PubMed: 21627112]

95. Pezacki JP, et al. Chemical contrast for imaging living systems: molecular vibrations drive CARS microscopy. Nat Chem Biol. 2011; 7:137-145. [PubMed: 21321552]

96. Chang PV, Dube DH, Sletten EM, Bertozzi CR. A strategy for the selective imaging of glycans using caged metabolic precursors. J Am Chem Soc. 2010; 132:9516-9518. [PubMed: 20568764]

97. Xie R, Hong S, Feng L, Rong J, Chen X. Cell-selective metabolic glycan labeling based on ligandtargeted liposomes. J Am Chem Soc. 2012; 134:9914-9917. [PubMed: 22646989]

98. Meldal M, Tornøe CW. Cu-catalyzed azide-alkyne cycloaddition. Chem Rev. 2008; 108:29523015. [PubMed: 18698735]

99. Kolb HC, Finn MG, Sharpless KB. Click chemistry: Diverse chemical function from a few good reactions. Angewandte Chemie-International Edition. 2001; 40:2004-+.

100. Huisgen R. 1,3-Dipolar Cycloadditions. Past and Future. Angew Chem Int Ed. 1963; 2:565-598. 


\section{Box 1}

The last decade has seen the remarkable development of highly selective chemical reactions that have allowed specific labeling of molecules in diverse biological contexts (Fig. 1) ${ }^{1,2}$. This two-step labeling and detection strategy involves metabolic or enzymatic installation of a chemical reporter that can be selectively reacted with functionalized probes for the visualization or identification of target molecules (Fig. 1a). Central to this chemical labeling strategy is the introduction of azide, alkyne and activated alkene groups as abiotic, minimally perturbing functionalities onto small molecules and their selective covalent reaction with activated phosphine-, alkyne- or azide-modified as well as tetrazine probes (Fig. 1). Since these functional groups are foreign to living organisms and are uniquely reactive with each other, this class of chemical reactions has been described as bioorthogonal ${ }^{1,2}$. The first example of these bioorthogonal reactions was the Staudinger ligation (Fig. 1b) ${ }^{27}$, which demonstrated that alkyl-azides can react with esterfunctionalized triphenylphosphine reagents to form covalent adducts in aqueous solution and on the surface of mammalian cells ${ }^{27}$ as well as in living animals ${ }^{2}$. Alternatively, the $\mathrm{Cu}(\mathrm{I})$-catalyzed azide-alkyne cycloaddition $(\mathrm{CuAAC})$ is a highly chemoselective reaction between alkyl-azides with terminal alkynes that form stable triazole products (Fig. $1 c)^{98-100}$. This prototypic click chemistry reaction is widely used in chemical synthesis and bioorthogonal labeling since the azide and alkyne groups can be used in either orientation, are relatively stable, and are readily accessible. The cytotoxicity of $\mathrm{Cu}(\mathrm{I}) \mathrm{can}$ preclude in vivo applications, but the development of activated cyclooctyne reagents has circumvented this limitation and has enabled imaging of bioorthogonal chemical reporters in living organisms (Fig. 1d) ${ }^{2}$. In addition to azide-alkyne cycloadditions, the development of tetrazine reagents has enabled selective and rapid bioorthogonal labeling of activated alkynes and alkenes through the Diels-Alder reaction (Fig. 1e) $)^{93,94}$. 


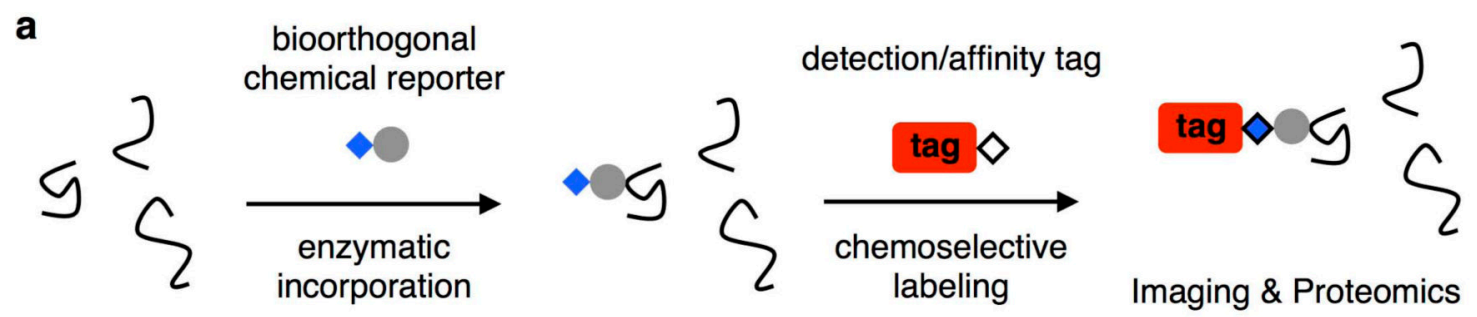

b<smiles>COC(=O)c1ccc(C)c2c3ccccc3p(-c3ccccc3)c12</smiles><smiles>[N-]C1C=C1</smiles><smiles>CCCCCCCCCCCCC</smiles><smiles>Cc1ccc(C(=O)NC2CC2)c(P(=O)(c2ccccc2)c2ccccc2)c1</smiles>

C

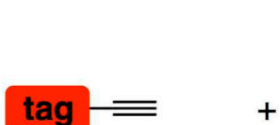

$+$
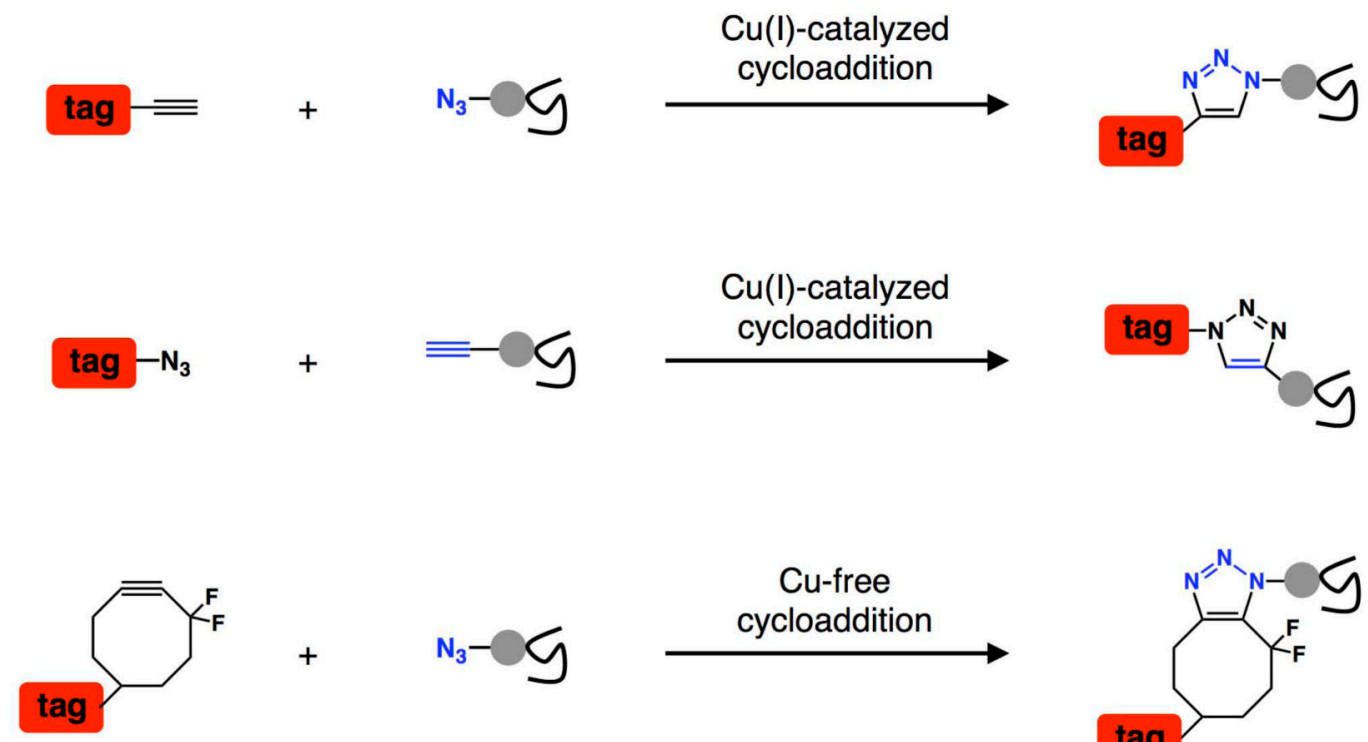

d
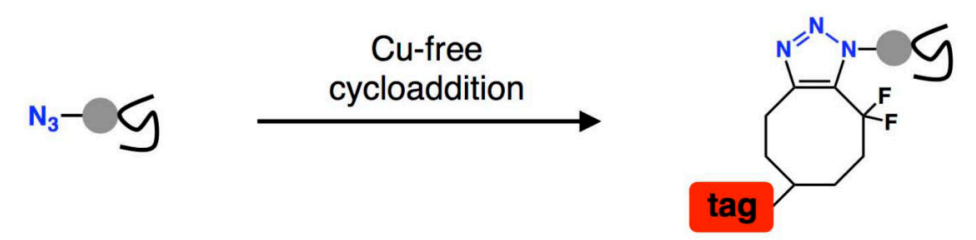

e

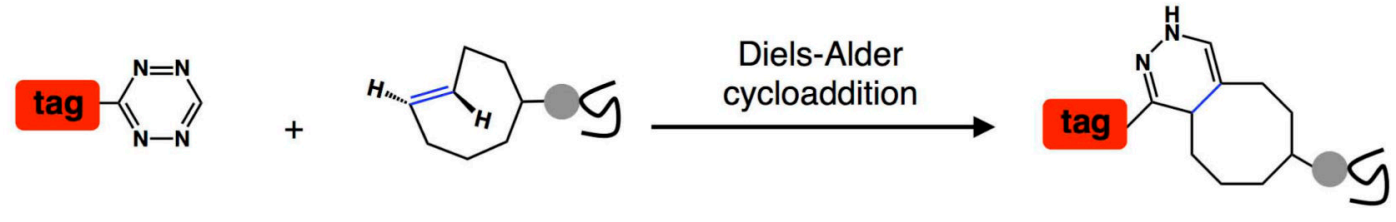

Figure 1.

Bioorthogonal labeling of biomolecules. a) Bioorthogonal chemical reporters and chemoselective reactions allow covalent labeling of biomolecules with detection or affinity tags for imaging or proteomics applications, respectively. b) Staudinger ligation allows labeling of alkyl-azides with triarylphoshine reagents. c) $\mathrm{Cu}(\mathrm{I})$-catalyzed cycloaddition between alkyl-azides and terminal alkynes affords triazole adducts, which can operate in both orientations. d) Activated cyclooctynes can react with alkyl-azides for $\mathrm{Cu}$-free labeling. e) Tetrazine reagents can undergo selective and rapid Diels-Alder reactions with activated alkenes such as trans-cyclooctenes. 
a
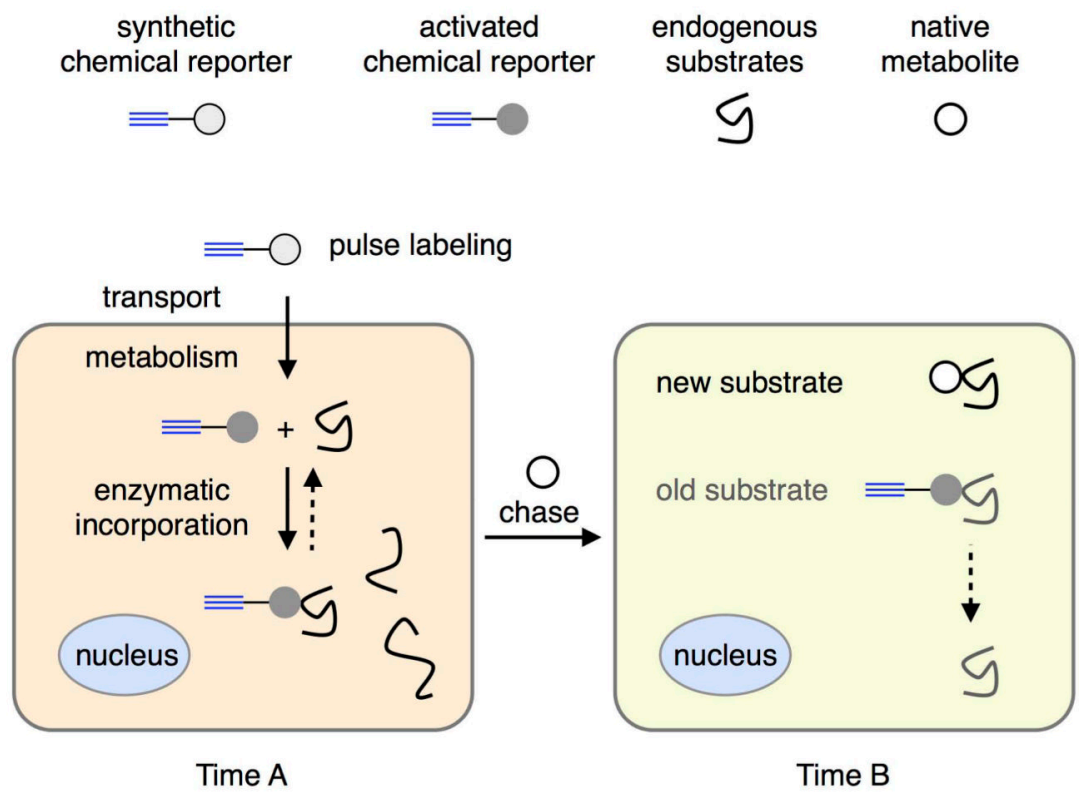

b

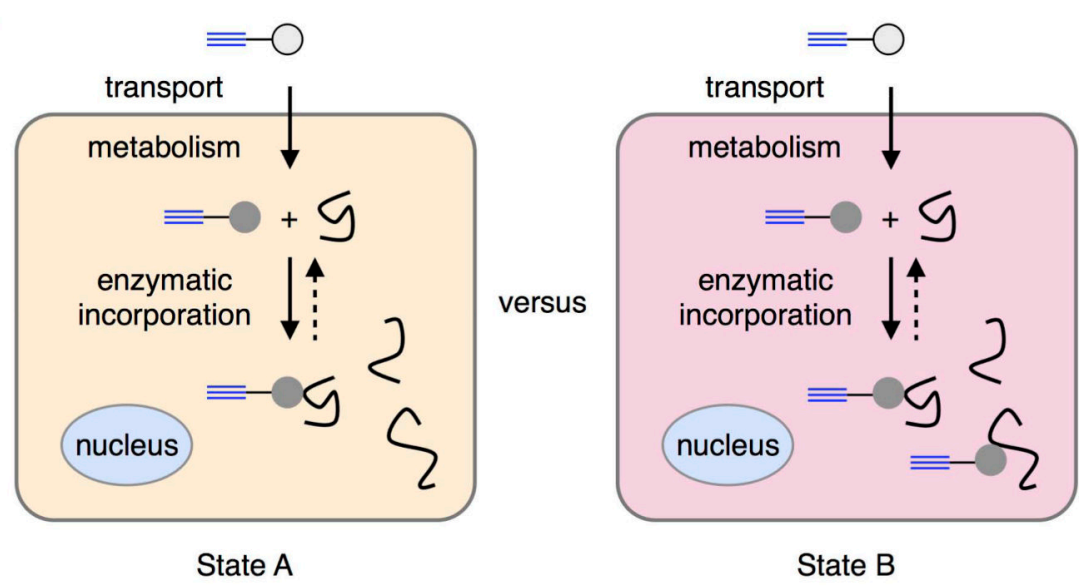

c

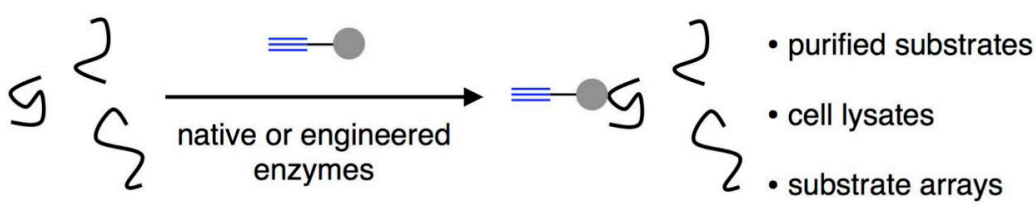

Figure 2.

Applications of bioorthogonal chemical reporters. a) Pulse-labeling of isolated cells or organisms with a chemical reporter leads to the metabolic incorporation of the reporter into targeted biomolecules. Subsequent labeling of cells with the native metabolites or differentially labeled reporter enables the monitoring of biomolecule turnover rates. $b$ ) Pulse-labeling of two distinct cellular populations or organisms allows the comparative analysis of their metabolically labeled biomolecule pools. c) The application of chemical reporters in cell lysates, with purified substrates, or in combination with substrate arrays allows for enzyme-specific substrate detection. 
a

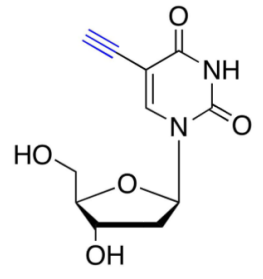

EdU

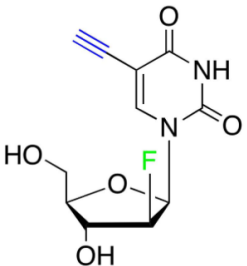

F-ara-EdU

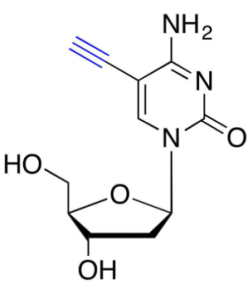

EdC<smiles></smiles><smiles>C#CCNc1ncnc2c1ncn2C1OCC(O)C(O)O1</smiles>

$\mathrm{N} 6 \mathrm{pA}$

b<smiles>CO[C@H]1C[C@@H](n2cc(CO)c(N)nc2=O)O[C@@H]1CO[Na]</smiles>

$5-\mathrm{hmC}$

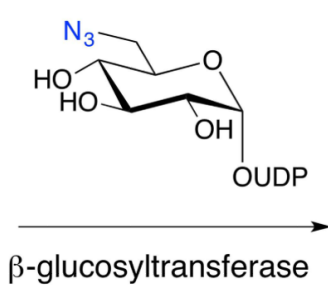

$\beta$-glucosyltransferase

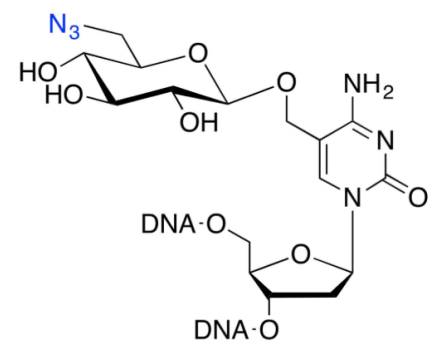

5-( $\left(\beta-6-\mathrm{N}_{3}-\mathrm{Glc}\right)-\mathrm{hmC}$

Figure 3.

Chemical reporters for nucleic acid synthesis and modifications. a) 5-ethynyl-2'deoxyuridine (EdU) is incorporated into DNA. b) 5-ethynyluridine (EU) is incorporated into RNA. c) 5-ethynyl-2'-deoxyfluorouridine (F-ara-EdU) is incorporated in to DNA. d) 5ethynyl-2'-deoxycytosine (EdC) in incorporated into DNA. e) N-6-propargyladenosine (N6pA) is incorporated into RNA and into mRNA polyadenylation tails. f) The DNA modification 5-hydroxymethylcytosine (5-hmc) can be enzymatically labeled with 6-azidoglucose for subsequent bioorthogonal detection. 
a<smiles>CC1CC=NC1C(=O)NCCCCC(N)C(=O)O</smiles>

Pyl

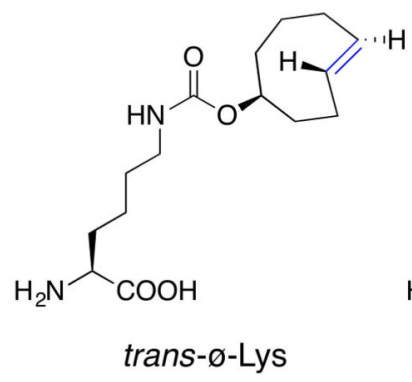<smiles>NC(CCCCNC(=O)OCC1CCC=CCC1)C(=O)O</smiles>

BCN-Lys

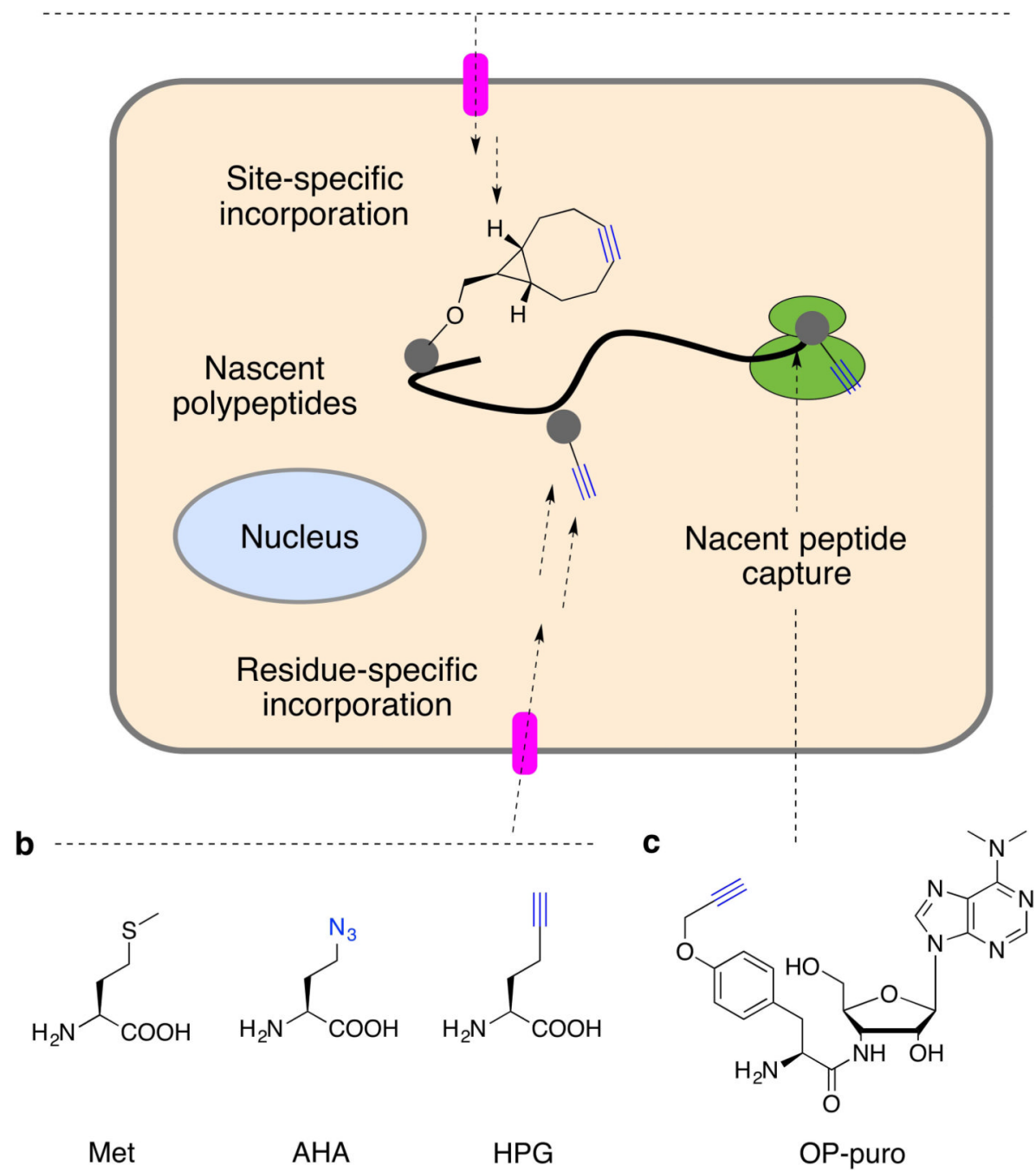

Figure 4.

Amino acid reporters for site- and residue-selective labeling of proteins. a) Analogs of the amino acid pyrrolysine (Pyl) with trans-cyclooctene (trans- $\varnothing$ ) or strained-cyclooctyne (bicyclo[6.1.0]non-4-yn-9-ylmethanol, BCN) groups can be site-selectively incorporated into individual proteins through the expression of orthogonal aminoacyl-tRNA-synthetase and tRNA. b) Analogs of methionine (Met) can be selectively incorporated throughout the bacterial or mammalian proteome to install an alkyne (homopropargylglycine, HPG) or azide (azidohomoalanine, AHA) group. c) O-propargyl-puromycin (OP-puro) covalently labels the $\mathrm{C}$-terminus of nascent peptides. 


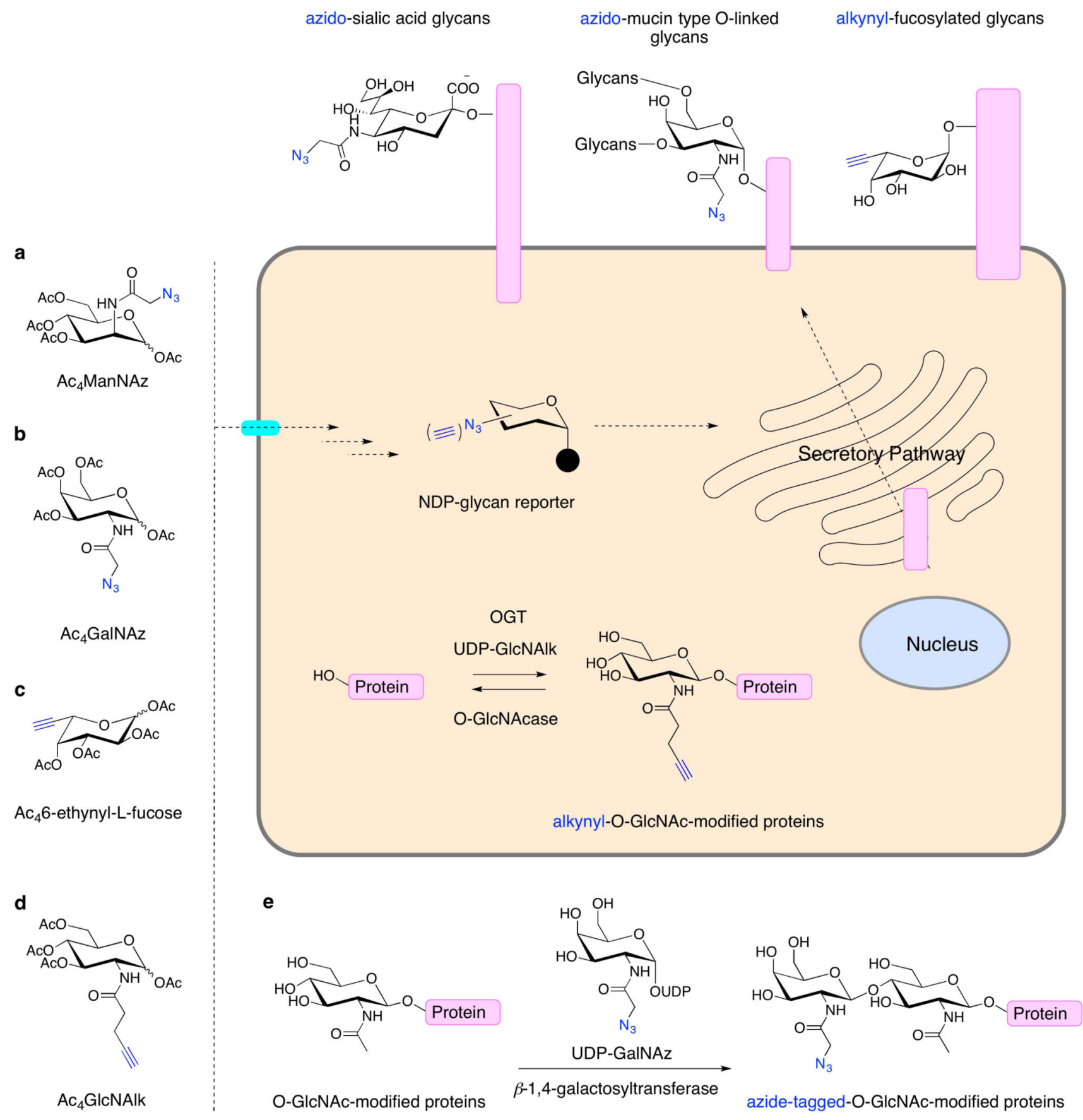

Figure 5.

Glycan chemical reporters. a) Peracetylated N-azidoacetyl-D-mannosamine ( $\left.\mathrm{Ac}_{4} \mathrm{ManNAz}\right)$ is metabolically incorporated into sialic acid glycans. b) Peracetylated N-azidoacetyl-Dgalactosamine $\left(\mathrm{Ac}_{4} \mathrm{GalNAz}\right)$ is metabolically incorporated into mucin type O-linked glycans. c) Peracetylated 6-ethynyl-L-fucose ( $\mathrm{Ac}_{4} 6$-ethynyl-L-fucose) is metabolically incorporated into fucosylated proteins. d) Peracetylated N-alkynylacetyl-D-glucosamine $\left(\mathrm{Ac}_{4}\right.$ GlcNAlk) is metabolically incorporated into O-GlcNAc modified proteins. e) OGlcNAc modified proteins can be chemoenzymatically labeled using a $\beta-1,4-$ galactosyltransferase that transfers GalNAz onto O-GlcNAc modified proteins. OGT, OGlcNAc transferase. 
a
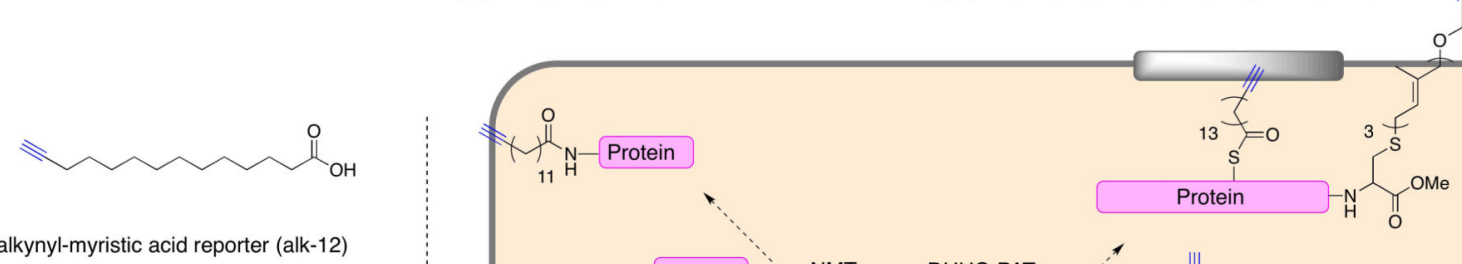

alkynyl-myristic acid reporter (alk-12)

b

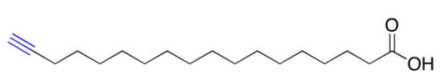

alkynyl-palmitic acid (alk-16, ODYA)

c

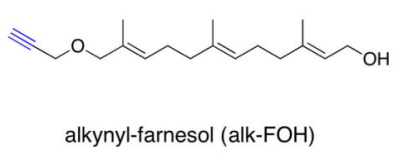

d

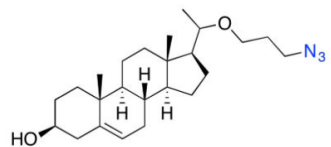

azido-cholesterol reporter

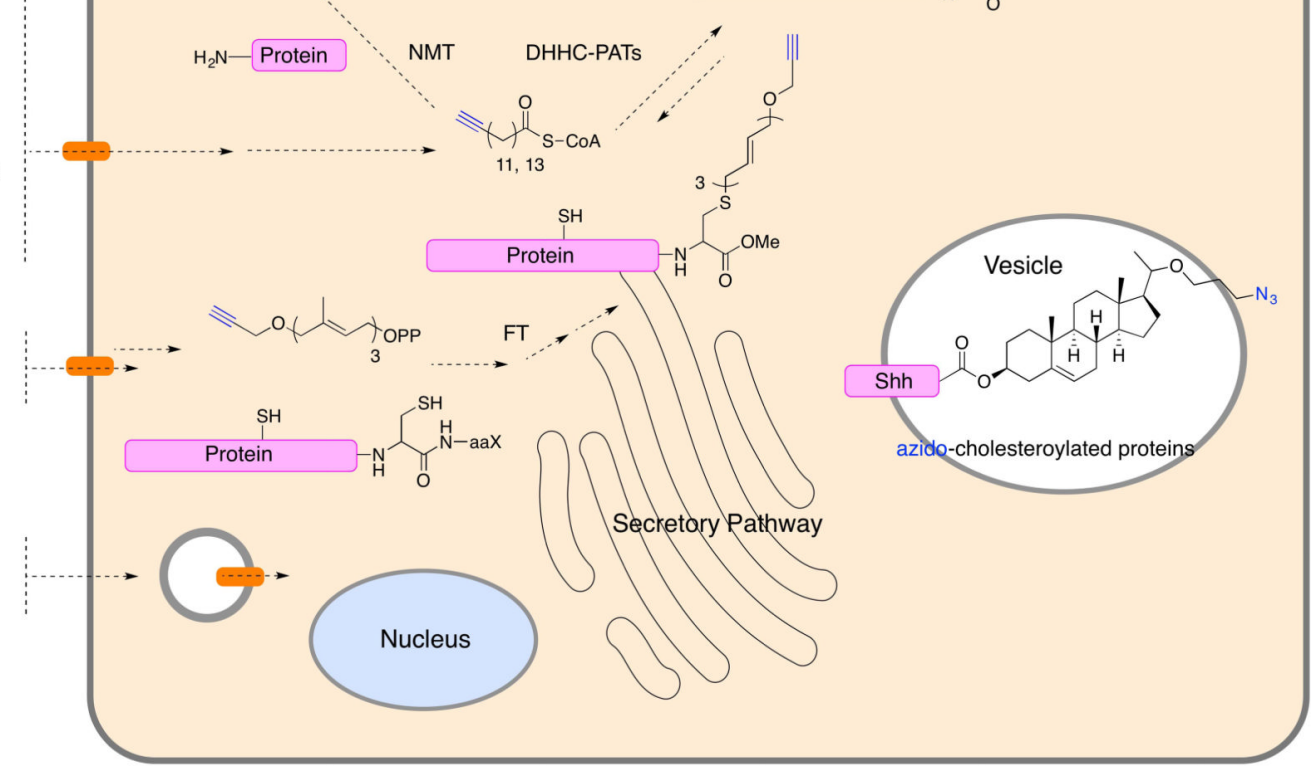

Figure 6.

Protein lipidation chemical reporters. a,b) Alkynyl-fatty acid reporters of different chain length enable selective metabolic labeling of fatty-acylated proteins. c) Alk-FOH allows metabolic labeling of S-farnesylated and S-geranylgeranylated proteins in mammalian cells. d) An azide analog of cholesterol can be metabolically incorporated onto the C-terminus of sonic hedgehog. NMT, N-myristoyltransferase. FT, farnesyltransferase. 
a

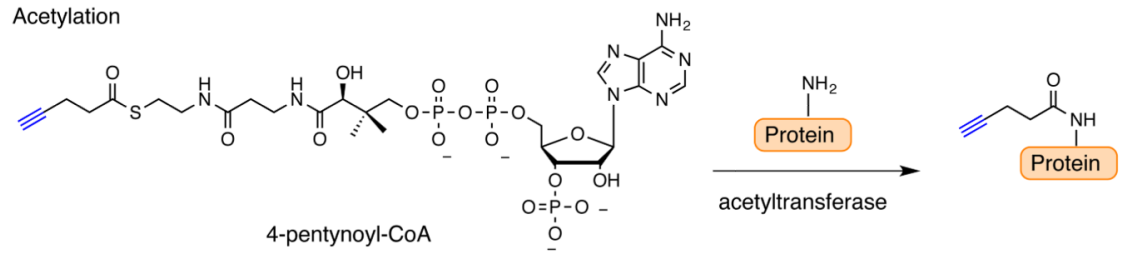

b Methylation<smiles>C#C/C=C/C[SH](CCC(N)C(=O)O)C[C@H]1O[C@@H](n2cnc3c(N)ncnc32)[C@H](O)[C@@H]1O</smiles>

AdoEnYn

C ADP-Ribosylation<smiles>NC(=O)c1cc[n+](CCl)cc1</smiles>

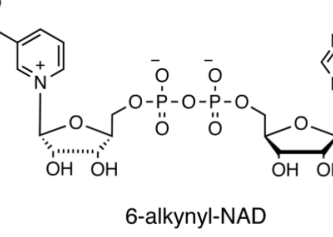
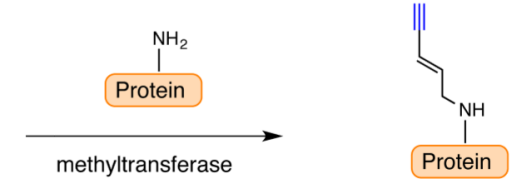

d AMPylation<smiles>C#CCNc1ncnc2c1ncn2C1OC(O)C(OP(C)(=O)OP(=O)(O)OP(=O)(O)OC)C(O)C1O</smiles><smiles>CC(C)CCOCCOCCO</smiles><smiles></smiles>

N-6-propargyl-ATP

e Phosphorylation

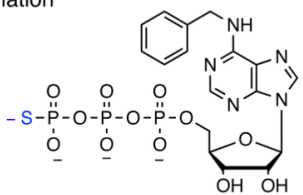

N-6-benzyl-ATP $\gamma$ S

Sulfenation
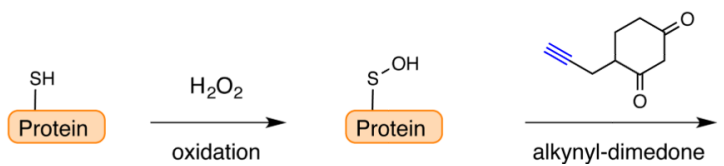

Figure 7.

Chemical reporters for other posttranslational modifications. a) Sodium-4-pentynoate allows metabolic labeling of acetylated proteins, while 4-pentynoyl-CoA can be used for in vitro analysis of acetyltransferase substrates. b) AdoEnYn and other SAM-based reporters have been developed to profile methyltransferase substrates. c) 6-alkynyl-NAD is a chemical reporter for mono- and poly-ADP-ribosylation. d) N-6-propargyl-ATP serves as a chemical reporter for protein AMPylation. e) N-6-benzyl-ATP $\gamma \mathrm{S}$ serves as a substrate for engineered kinases and allows selective modification with a nitrobenzyl-hapten for antibody detection as well as enrichment for proteomic studies. f) The oxidative modification of cysteines to 
sulfenic acid can be monitored by reaction with an alkynyl-dimedone reagent for subsequent bioorthogonal detection of protein sulfenation. 